\title{
A salt tracer test monitored with surface ERT to detect preferential flow and transport paths in fractured/karstified limestones
}

\author{
Tanguy Robert ${ }^{1}$, David Caterina ${ }^{1}$, John Deceuster ${ }^{2}$, Olivier Kaufmann ${ }^{2}$, and Frédéric Nguyen ${ }^{3}$
}

\begin{abstract}
In hard-rock aquifers, fractured zones constitute adequate drinking water exploitation areas but also potential contamination paths. One critical issue in hydrogeological research is to identify, characterize, and monitor such fractured zones at a representative scale. A tracer test monitored with surface electrical resistivity tomography (ERT) could help by delineating such preferential flow paths and estimating dynamic properties of the aquifer. However, multiple challenges exist including the lower resolution of surface ERT compared with crosshole ERT, the finite time that is needed to complete an entire data acquisition, and the strong dilution effects. We conducted a natural gradient salt tracer test in fractured limestones. To account for the high transport velocity, we injected the salt tracer continuously for four hours at a depth of $18 \mathrm{~m}$. We monitored its propagation with two parallel ERT profiles perpendicular to the
\end{abstract}

groundwater flow direction. Concerning the data acquisition, we always focused on data quality over temporal resolution. We performed the experiment twice to prove its reproducibility by increasing the salt concentration in the injected solution (from 38 to $154 \mathrm{~g} / \mathrm{L}$ ). Our research focused on how we faced every challenge to delineate a preferential flow and solute transport path in a typical calcareous valley of southern Belgium and on the estimation of the transport velocity (more than $10 \mathrm{~m}$ /hour). In this complex environment, we imaged a clear tracer arrival in both ERT profiles and for both tests. Applying filters (with a cutoff on the relative sensitivity matrix and on the background-resistivity changes) was helpful to isolate the preferential flow path from artifacts. Regarding our findings, our approach could be improved to perform a more quantitative experiment. With a higher temporal resolution, the estimated value of the transport velocity could be narrowed, allowing estimation of the percentage of tracer recovery.

\section{INTRODUCTION}

Fractured zones are extremely important to identify and to characterize because they are preferential groundwater flow and solute transport paths (Berkowitz, 2002). They constitute adequate drinking water exploitation areas but also potential contamination paths. Important issues in hydrogeological research, as was pointed out by Post (2005), are not so much the mathematical descriptions of processes or techniques but their applications to real-world data and cases. In this framework, innovative techniques or methodologies are needed to locate and characterize fractured zones in hard-rock aquifers as well as to monitor groundwater flow or solute transport through them.
Numerous field techniques and methodologies exist to obtain hydrogeological information about fractured aquifers. Classical pumping tests allow estimating the hydraulic conductivity in an area around the well and evaluating the absence or presence of hydraulically conductive fractures. These tests are useful but not flawless (Wu et al., 2005) because they depend on strong assumptions such as Theis' homogeneous aquifer assumption (Fetter, 2001). Pumping tests evolved into hydraulic tomography which allows obtaining high resolution images of the hydraulic conductivity distribution (Yeh and Liu, 2000; Liu et al., 2002; Zhu and Yeh, 2005; Illman and Tartakovsky, 2006; Zhu and Yeh, 2006; Hao et al., 2008; Illman et al., 2008; Yin and Illman, 2009). However, this method requires several wells and prior knowledge about the location of fractures.

\footnotetext{
Manuscript received by the Editor 19 August 2011; revised manuscript received 16 November 2011; published online 27 February 2012.

${ }^{1}$ University of Liege, Department ArGEnCo, Applied Geophysics, Liege, Belgium; F.R.I.A.-F.N.R.S., Brussels, Belgium. E-mail: tanguy.robert@ulg.ac.be; david.caterina@ulg.ac.be.

${ }^{2}$ University of Mons, Faculty of Engineering, Fundamental and Applied Geology Department, Mons, Belgium. E-mail: john.deceuster@umons.ac.be; olivier.kaufmann@umons.ac.be.

${ }^{3}$ University of Liege, Department ArGEnCo, Applied Geophysics, Liege, Belgium. E-mail: f.nguyen@ulg.ac.be.

(C) 2012 Society of Exploration Geophysicists. All rights reserved.
} 
Geophysics is helpful to characterize fractured zones. Many examples in the literature prove the utility of geophysical surveys to characterize fractured aquifers (Fagerlund and Heinson, 2003; Boadu et al., 2005; Porsani et al., 2005; Sharma and Baranwal, 2005; Day-Lewis et al., 2006; Yadav and Singh, 2007; Suski et al., 2008; Robert et al., 2011).

Electrical resistivity tomography (ERT) allows practitioners to identify fractured or karstified areas that are expected to exhibit lower bulk electrical resistivity (Robert et al., 2011). However, ERT fails to identify local groundwater flow direction because it is not sensitive to the groundwater fluxes, in contrast to the self-potential (SP) technique (Corwin and Hoover, 1979; Sill, 1983; Fournier, 1989; Aubert and Atangana, 1996). SP data have been used to detect flow paths (Fagerlund and Heinson, 2003; Revil et al., 2005; Jardani et al., 2006; Suski et al., 2008), leakages in dams (Al-Saigh et al., 1994; Bolève et al., 2009), and more recently to infer by inversion the fluxes within the preferential flow path (Jardani et al., 2007; Bolève et al., 2009). The last requires the knowledge of the streaming potential coupling coefficient (Revil et al., 1999) and supposes that the electrokinetic effect is the dominant contribution of the SP signals. To detect preferential solute transport paths with ERT, one must highlight these zones by changing their electrical resistivity in an appropriate way (e.g., injection of a salt tracer) and then monitor these changes (Binley et al., 2002a; Kemna et al., 2002; Singha and Gorelick, 2005; Vanderborght et al., 2005; Cassiani et al., 2006).

Tracer tests allow estimating parameters that describe groundwater flow, such as flow direction and preferential flow paths, as well as solute transport processes such as advection, diffusion, or dispersion (e.g., Ptak et al., 2004). The success of a tracer test highly depends on the number and localization of the wells constituting the monitoring network and on the injection procedure. In heterogeneous porous or fractured aquifers, the tracer arrival can be totally missed if no monitoring well crosses the main flow path or if the injection is not suitable. Appropriate noninvasive methodologies are therefore necessary to identify preferential flow paths prior to the monitoring-network setup and to estimate transport velocities or dispersion/dilution effects to set up the injection. In this context, geophysics can provide key information, such as the position of fractured areas, the heterogeneity of the medium, or the presence of low permeability layers. In a time-lapse mode, geophysics can further provide flow and transport information, such as velocity or dispersivity.

In the past two decades, ERT has been used to monitor salt tracer tests or water infiltration through the vadose zone in relatively homogeneous or stratified hydrogeological systems either in the laboratory (Binley et al., 1996a; Slater et al., 2000, 2002; Koestel et al., 2008) or in test sites (Slater et al., 1997a; al Hagrey and Michaelsen, 1999; Day-Lewis et al., 2003; Singha and Gorelick, 2005; Cassiani et al., 2006; Müller et al., 2010). Table 1 presents a nonexhaustive list of surveys that were designed to monitor water infiltration or salt tracer propagation in the laboratory and in the field. Note the low number of studies in complex aquifers involving fractures and karsts.

In heterogeneous porous media, Kemna et al. (2002) assessed the contribution of crosshole ERT to image and characterize subsurface solute transport processes during a tracer test $(\mathrm{NaBr})$ at the Krauthausen test site in Germany. These authors proved that transport properties could be retrieved satisfactorily from ERT time- lapse results for this specific hydrogeological context (a shallow unconfined aquifer composed of sand and gravel surrounding a clayey layer).

Crosshole radar and resistivity measurements have been used by Binley et al. (2002a) to monitor a controlled tracer test in the vadose zone of a field site in the UK Sherwood Sandstone. Both methods successfully showed a clear vertical migration of the tracer (slightly salty supply water) through the vadose zone. This experiment allowed the authors to monitor changes in moisture content thanks to appropriate petrophysical relationships.

Cassiani et al. (2006) used surface ERT to identify hydraulic connections between a shallow unconfined aquifer and a deeper confined aquifer in the Po River alluvial plain in Italy. All these results were controlled and validated with ground-truth information such as tracer concentrations measured in groundwater samples collected at observation wells.

In fractured media, Slater et al. (1997a) showed that crosshole ERT monitoring is a suitable methodology for the determination of hydraulically conductive fractures in a limestone environment. They used an intrusion of saline water, artificially created by pumping a large amount of groundwater — 6500 liters per hour — for three weeks into a limestone aquifer close to the coast as a natural tracer and were able to correlate the percentage change of resistivity with known cavities. However, if crosshole ERT offers greater resolution than surface measurements, its application is not possible everywhere due to the lack of prior information concerning fracturing or simply due to financial or logistical constraints.

Nimmer et al. (2007) used surface and crosshole ERT measurements to monitor the dilution of a preexisting potassium chloride plume in a fractured basalt environment. They were able to image the increase of resistivity due to the dilution of the plume with surface measurements, but no preferential transport path was distinguished (either for individual fractures or for fractured zones). Nevertheless, crosshole ERT allowed the authors to obtain some information about transmitting fractures or fractured zones.

Theoretically, ERT offers the possibility to fully recover the injected tracer. Practically, it is often limited by the sensitivity distribution of the inverted models (Müller et al., 2010). When the changes of electrical resistivity related to the tracer presence occur in zones with low sensitivity, the tracer can be only partially recovered and even totally missed (Kemna et al., 2002). Great care is required when setting up the experiment and the ERT sequences to ensure that the zones where the tracer propagation is expected are sensitive enough to detect the tracer arrival.

A higher concentration of the tracer in the injected solution can generally be used to counterbalance the dilution effects. However, this leads to denser tracer solutions, which could sink down in the aquifer rather than flow through the natural path. Such a problem arose in an experiment at the Krauthausen test site in Germany (Kemna et al., 2002), where the tracer sank down due to density effects and low hydraulic gradients.

These density problems can be strongly reduced if the tracer is transported rapidly, for example through preferential paths such as fractures or karstic conduits. Still, high transport velocities are a challenge in ERT monitoring (and in any other geophysical method) regarding the finite time that is necessary to complete the acquisition of an entire ERT sequence (Day-Lewis et al., 2002; Day-Lewis et al., 2003; Miller et al., 2008). 
Table 1. Nonexhaustive review of the previous studies employing ERT (or DC surveys) to monitor hydrogeological processes such as water infiltration and salt tracer propagation. The ability of ERT to image salt tracer propagation was clearly demonstrated in the laboratory or in shallow alluvial aquifers. However, except for a few studies that investigated fractured bedrock, we were not able to find a reference that investigated the ability of ERT to monitor a salt tracer test in complex fractured/karstified limestones or at a greater depth with only surface measurements. This study was then designed to investigate whether ERT and a salt tracer test could be combined to image and characterize a preferential solute transport path through fractured limestones. Note that MALM is "mise a la masse" and that the difference between a positive and a negative tracer is related to the effect of the tracer on the bulk electrical resistivity. A positive tracer (e.g., salty water; our case) decreases the bulk electrical resistivity, whereas a negative tracer increases it (e.g., pure water).

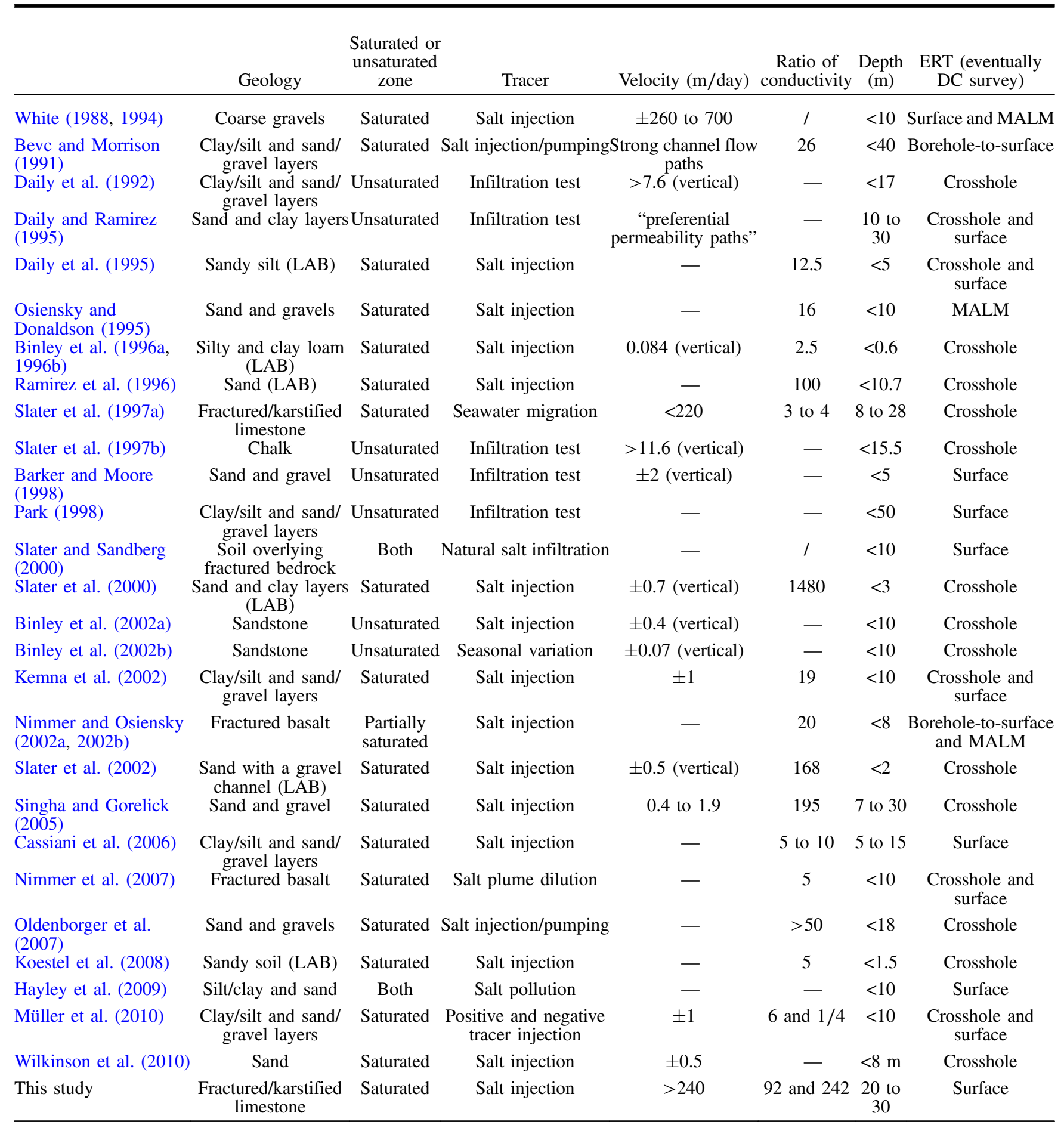


The aim of our study was to set up a qualitative monitoring experiment to confirm and characterize preferential flow paths at a small-basin scale in a fractured/karstified limestone aquifer using surface ERT measurements. Because previous workers focused mainly on crosshole ERT and on shallow aquifers (Table 1), we performed this experiment to prove the ability of surface ERT to image a preferential solute transport path at a greater depth (20 to $30 \mathrm{~m}$ ). A previous geophysical study (Robert et al., 2011) allowed us to identify potential fractured zones and/or karstic conduits in carboniferous limestones of southern Belgium and to position wells for hydrogeological studies. We used one of these sites to perform this experiment.

We conducted a continuous natural gradient salt tracer test to characterize a preferential flow path in terms of geometry and direction but also in terms of solute transport properties. In complex heterogeneous systems, such tracer tests monitored with surface ERT constitute a real challenge because of the strong dilution effects (which will reduce the "field of view" of ERT) and the high transport velocities (for which great care on the acquisition sequences is needed). Moreover, a good compromise between depth of investigation and resolution was needed because previous results (Robert et al., 2011) showed that the targeted fractured zone was at a depth of $20 \mathrm{~m}$.

The paper is organized as follows. We will present our experimental site in terms of location, geology, and hydrogeology. We will then describe our experimental methodology, the way we

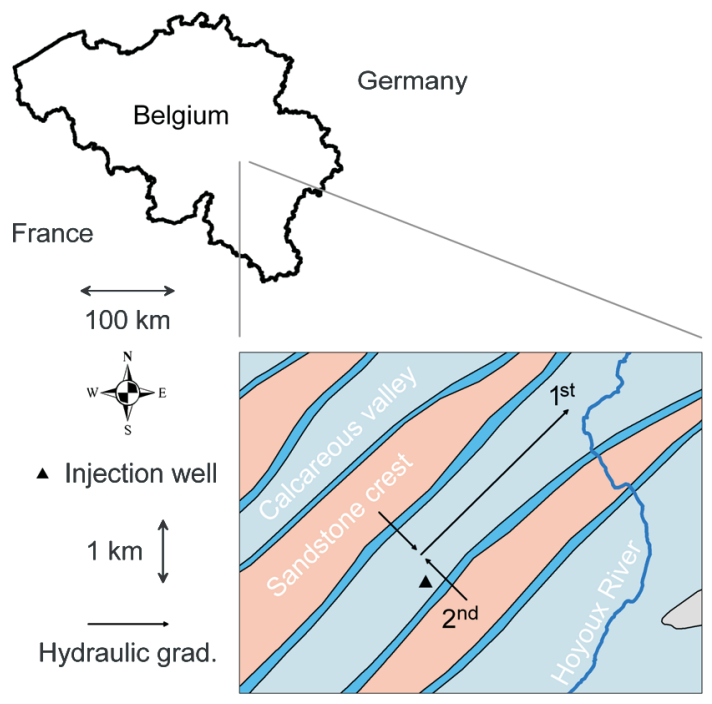

Figure 1. The Dinant Synclinorium geological structure (southern Belgium), containing our experimental area, is a succession of sandstone anticline (crest) and calcareous syncline (valley). An impermeable shale layer is also situated between the limestones and the sandstones. Calcareous valleys form aquifers that are very complex because they are highly fractured and karstified. In such valleys, groundwater flow is constrained by two perpendicular hydraulic gradients. The first gradient (estimated at 0.01 ) is linked to the Hoyoux River that flows northeast of the injection well. This river imposes a base level which constrains groundwater to flow toward it. The second gradient (ranging from 0.005 to 0.02 in different synclines) is linked to the flanks of the calcareous valley, with groundwater flowing from the flanks of the valley toward its center. Because the injection well is located on the southern flank of the calcareous valley, groundwater flow is influenced by both gradients. estimated the depth of investigation, the background-resistivity variations and the inversion algorithm. Results associated with two different tracer injections that only differ by the salt concentration will then be discussed. Conclusions and recommendations will finally be presented.

\section{EXPERIMENTAL SITE}

To prove that monitoring a salt tracer test with ERT is feasible in complex hard-rock systems, we needed to conduct the experiment on a site where preferential flow paths were identified. The Havelange site, situated in southern Belgium (Figure 1), meets these requirements because fractured zones and karstic conduits were previously identified with ERT and SP profiles (Robert et al., 2011). Our injection well was drilled on the basis of the results of these geophysical profiles and this borehole crosses numerous fractures between 8 and $20 \mathrm{~m}$ below ground surface. The hydraulic conductivity of this well was estimated at $10^{-4} \mathrm{~m} / \mathrm{s}$ by a pumping test (Brouyère et al., 2009). This is only an order of magnitude because the drawdown during the pumping test was extremely low $(0.69 \mathrm{~m}$ with a pumping rate of $20 \mathrm{~m}^{3} / \mathrm{h}$ ).

The Havelange site lies in a carboniferous limestone syncline which is a part of the Dinant Synclinorium geological structure (Figure 1). This synclinorium is a succession of late Tournaisian-Visean calcareous synclines and late Famennian sandstones anticlines corresponding to the main valleys and crests, respectively. An impermeable shale layer is also situated between the limestones and the sandstones. All these structures are oriented northeast-southwest (Figure 1).

The carboniferous limestones in the Havelange site are highly fractured and karstified and create a complex groundwater flow system. These fractured zones as well as the karstic conduits can be evidenced in nearby quarries. The Havelange calcareous syncline is about $800 \mathrm{~m}$ wide and $6500 \mathrm{~m}$ long, and the difference in elevation between the nearby sandstone crests and this particular limestone valley is about $60 \mathrm{~m}$. Therefore, we included the topography in the ERT data inversion.

In the studied area, groundwater flow is controlled by two perpendicular hydraulic gradients (Figure 1). The first gradient, along the main fold axis direction (northeast-southwest), is prescribed by the nearby Hoyoux River (Brouyère et al., 2009) and can be estimated at about 0.01 - that is, $1 \mathrm{~m}$ (elevation) per $100 \mathrm{~m}$ (along the topography). As a consequence, groundwater flows toward the northeast in the Havelange syncline. The second gradient is linked to the flanks of the calcareous valley, with groundwater flowing from the flanks of the valley toward its center (Figure 1). This gradient is difficult to estimate given the absence of piezometers in this area. Nevertheless, in a nearby syncline, it ranges between 0.005 and 0.02 - that is, between 0.5 and $2 \mathrm{~m}$ (elevation) per $100 \mathrm{~m}$ (along the topography), respectively.

In the vicinity of the injection well, situated on the southern flank of the syncline, both gradients play an important role but it is difficult to determine in what proportions. It was however crucial to estimate the local groundwater flow direction to position our ERT profiles correctly. The results of an SP profile (Robert et al., 2011) showed that the hydraulic gradient linked to the southern flank of the valley could not be neglected. By assuming that both gradients were equal in proportions, we estimated the local groundwater flow direction to be $\mathrm{N} 15^{\circ} \mathrm{E}$. 
The transport velocity values in such complexly fractured and karstified systems are extremely variable with values ranging between 5 and $225 \mathrm{~m} /$ hour. Results of classic tracer tests performed in some calcareous valleys of the Dinant and Namur Synclinorium geological structures are summarized in Brouyère et al. (2009).

The injection well is equipped with a PVC casing with a diameter of $125 \times 112 \mathrm{~mm}$ (ext $\times$ int). Screens (with an aperture of $2 \mathrm{~mm}$ ) begin at a depth of $16.4 \mathrm{~m}$ and extend to the bottom of the well at $45 \mathrm{~m}$. The diameter of the well is $250 \mathrm{~mm}$. The gravel pack (4-6 $\mathrm{mm}$ caliber) has a radius of $62.5 \mathrm{~mm}$ through the entire screened zone. We measured the water table at a depth of $11.38 \mathrm{~m}$ and this value was constant during the entire experiment.

\section{EXPERIMENTAL METHODOLOGY}

We monitored the salt tracer propagation with two parallel ERT profiles placed perpendicularly to the estimated local groundwater flow direction (approximately $\mathrm{N} 15^{\circ} \mathrm{E}$ ), to cross the salt tracer propagation path and better constrain it. These two transverse ERT profiles were placed $15 \mathrm{~m}$ and $30 \mathrm{~m}$ from the injection well.

We also placed a third longitudinal ERT profile (called L) in the estimated local groundwater flow direction with the aim of observing the propagation of the salt tracer in time. However, it was not aligned with the real tracer transport path (about 5 to $10^{\circ}$ away) and no significant anomalies were observed on the results. These results are therefore not presented in this paper.

We chose to set up the ERT profiles to have a sufficient depth of investigation $(30 \mathrm{~m})$ by taking a minimum of $200 \mathrm{~m}$ for the length of each ERT profile (Table 2).
To deal with resolution problems, we used two different electrode spacings for both transverse profiles (Table 2). The nearest one (called P1) has 72 electrodes with a spacing of $3 \mathrm{~m}$ (213 m long), whereas the farthest one (called P2) has 48 electrodes with a spacing of $5 \mathrm{~m}$ ( $235 \mathrm{~m}$ long). We left the cables and the electrodes in place during the 3 days of the experiment.

We measured every electrode location with a differential GPS (Leica GPS1200, Leica Geosystems) to take the topography into account. The vertical and horizontal accuracies are estimated to be better than $3 \mathrm{~cm}$.

To establish the background when there is no injection, we collected two data sets (on 15 and 16 March 2010, respectively).

In this experiment, we needed to ensure that the tracer would not sink into the well but rather flows through the fractured zone. We therefore placed a packer in the well at a depth of $20 \mathrm{~m}$ (lower limit of the fractured zone). The strong hydraulic gradients of the studied area result in high transport velocities that prevent the salt tracer from sinking once flowing in the fractured zone.

We performed the tracer experiment twice (on 16 March 2010 and 17 March 2010) to demonstrate its reproducibility and to address uncertainties associated with dilution effects (by increasing the salt concentration between both tests) and the local groundwater flow direction (by eventually changing the location of the longitudinal ERT profile). The only difference between the two tests is the salt $(\mathrm{NaCl})$ concentration in the injected solution, which is $38 \mathrm{~g} / \mathrm{L}$ for the first test (Table 3) and $154 \mathrm{~g} / \mathrm{L}$ for the second test. To achieve this, we used $384 \mathrm{~kg}$ of salt for both tests $(76 \mathrm{~kg}$ for test 1 and $308 \mathrm{~kg}$ for test 2).

Table 2. ERT parameters. The Rs check option allows the measurement and storage of the contact resistances.

\begin{tabular}{|c|c|c|c|}
\hline ERT parameters & Profile $1(\mathrm{P} 1)$ & Common to both profiles & Profile $2(\mathrm{P} 2)$ \\
\hline Electrode array & \multicolumn{3}{|c|}{ Dipole-dipole $(\mathrm{n} \leq 6)$} \\
\hline Electrode number & 72 & & 48 \\
\hline Data points & 1225 & & 629 \\
\hline Electrode spacing & $3 \mathrm{~m}$ & & $5 \mathrm{~m}$ \\
\hline Length of the profile & $213 \mathrm{~m}$ & & $235 \mathrm{~m}$ \\
\hline Depth of investigation (DOI) & $\pm 30 \mathrm{~m}$ & & $\pm 50 \mathrm{~m}$ \\
\hline Distance from injection well & $15 \mathrm{~m}$ & & $30 \mathrm{~m}$ \\
\hline Number of stacks & \multicolumn{3}{|c|}{3 to 6} \\
\hline Quality factor & \multicolumn{3}{|c|}{$1 \%$} \\
\hline Current injection time window $\left(\mathrm{T}_{\mathrm{on}}\right)$ & \multicolumn{3}{|c|}{$1 \mathrm{~s}$} \\
\hline Rs check & \multicolumn{3}{|c|}{ For selected sequences } \\
\hline Reciprocal measurements & \multicolumn{3}{|c|}{ For background sequences } \\
\hline Sequence optimization & \multicolumn{3}{|c|}{ Up to 6 channels used (because $n \leq 6$ ) } \\
\hline Syscal parameters & \multicolumn{3}{|c|}{$\mathrm{V}_{\mathrm{p}}=800 \mathrm{mV}-\mathrm{Vab} \max =800 \mathrm{~V}$} \\
\hline Duration of the sequence & 43 min (55 with Rs check) & & 20 min (26 with Rs check) \\
\hline Static inversion parameters & \multicolumn{3}{|c|}{ Robust data constraint and blocky inversion } \\
\hline Time-lapse inversion parameters & & $\begin{array}{l}\text { Robust smoothness constrain } \\
\text { taneous inversion (data diffe } \\
\text { background image as a refe }\end{array}$ & \\
\hline
\end{tabular}


Given the expected high transport velocities, we injected the tracer solution during 4 hours to maintain the changes in electrical resistivity long enough to visualize the salt tracer propagation. The injection rate was limited to approximately $500 \mathrm{~L} / \mathrm{h}$ to preserve the natural hydraulic gradient of the area, as evidenced by the hydraulic head observed in the injection well.

One critical issue with fast transport processes is the finite time that is required to complete the data collection of one entire ERT image (e.g., Miller et al., 2008). To reduce the data acquisition time, we optimized a dipole-dipole configuration with $\mathrm{n} \leq 6$ for multichannel acquisition (maximum 6 channels used) by sorting the sequence in a way that no pair of potential electrodes was used after a transmitter current injection. This also allowed us to scan the subsurface from one side of the profile to the other one. Electrical data were acquired with an IRIS SYSCAL PRO device.

Another way to reduce the data acquisition time is to reduce the transmitter-current-injection time window. However, this could lead to poorer data quality. In this experiment, we chose a current injection time window equal to 1 second with minimum three (maximum six) stacks performed with a quality factor of $1 \%$. These parameters resulted in a duration of about 45 minutes for $\mathrm{P} 1$ and 25 minutes for P2 and L. Although this parameter set is not the fastest one, we believed that the data quality was more important than gaining extra time-lapse images, at this stage.

We designed the acquisition of ERT images with the idea to move away from the injection well during the time elapsed. A sequence was then designed as follows. First, the longitudinal profile L (no results are shown in this work) was collected (25 min), then P1 (45 min) and finally, P2 (25 min). A complete sequence of acquisition (L, P1, and P2) took approximately 1.5 hours. Data acquisition started approximately 40 minutes after the beginning of the injection for the first test (10 minutes for the second test).

We monitored the fluid electrical conductivity (with a YSI 650 MDS multiparameter probe) throughout all the experiment in the middle of the injection window at a depth of $18 \mathrm{~m}$, to know exactly when the tracer injection into the aquifers was complete and therefore when to stop measuring. We acquired seven complete sequences of acquisition for both tests until the ratio between the electrical conductivity measured in the well and the natural groundwater electrical conductivity was less than a tenth of its maximum.
Every measurement of electrical conductivity presented is for a groundwater temperature that was equal to $9.85^{\circ} \mathrm{C}$ throughout the experiment.

The electrical conductivity of groundwater before injection was measured in the well at about $0.52 \mathrm{mS} / \mathrm{cm}$, corresponding to mineralized water (mostly calcium, magnesium, and carbonate). The injected solution containing the salt tracer had an electrical conductivity of about $48 \mathrm{mS} / \mathrm{cm}$ for a salt concentration of $38 \mathrm{~g} / \mathrm{L}$ (test 1), whereas it was $147 \mathrm{mS} / \mathrm{cm}$ for $154 \mathrm{~g} / \mathrm{L}$ (test 2). The ratio of electrical conductivity between the injected solution and the natural groundwater is equal to 92 (test 1) and 282 (test 2). This corresponds to nearly two and three orders of magnitude for test 1 and test 2, respectively.

Table 1 presents a comparison of our tracer test parameters with previous studies. Here, we did not perform a complete review of the literature but we rather wanted to highlight the lack of such studies in complex aquifers involving fractures and karsts. Note that the ratio of electrical conductivity of the injected solution between both tests is only tripled, while the salt concentration is quadrupled. Indeed, the relationship between salt concentration and electrical conductivity does not remain linear at high concentration (e.g., Kemna et al., 2002). Note also that we injected the tracer at the top of the well and that it was already diluted before flowing into the fractured area. Hence, the maximum ratio measured in the well was about 80 for test 1 and 150 for test 2, whereas the same ratio in the injected solution was 92 for test 1 and 282 for test 2 .

\section{ERROR ANALYSIS}

To estimate the data noise level, we performed reciprocal measurements (swapping current and potential electrodes) on selected sequences. The reciprocal error, which is the difference between normal and reciprocal electrical resistances, is often used as a data quality indicator (LaBrecque et al., 1996; Slater et al., 2000; Koestel et al., 2008).

When comparing normal and reciprocal measurements, it is essential to collect the data sets under identical conditions. Therefore, in our experiment where high transport velocities were expected, it was useless to collect reciprocal measurements during the entire salt tracer injection. Thus, we collected reciprocal measurements only for both background sequences as well as for the sequences between

Table 3. Tracer test parameters.

\begin{tabular}{lcc}
\hline Tracer test parameters & First injection & Common to both injections \\
\hline $\begin{array}{l}\text { Date } \\
\text { Injection duration }\end{array}$ & 16 March 2010 & $4 \mathrm{~h}$ \\
$\begin{array}{l}\text { Injection rate } \\
\text { Injected salt concentration }\end{array}$ & $38 \mathrm{~g} / \mathrm{L}$ & $500 \mathrm{~L} / \mathrm{hour}$ \\
$\begin{array}{l}\text { Electrical conductivity of the injected solution } \\
\text { Groundwater electrical conductivity }\end{array}$ & $48 \mathrm{mS} / \mathrm{cm}$ & $0.52 \mathrm{mS} / \mathrm{cm}$ \\
$\begin{array}{l}\text { Ratio of electrical conductivity } \\
\text { Water table depth }\end{array}$ & 92 & $11.38 \mathrm{~m}$ \\
Injection depth window & & From $16.4 \mathrm{~m}$ (screens) to $20 \mathrm{~m}$ (packer) \\
\end{tabular}


the first and second tests. The analysis of the reciprocal error distribution shows that the average noise level varies less than $0.1 \%$ from 15 March to 17 March 2010.

The acquisition of reciprocal measurements is also time-consuming because a sequence needs to be collected twice. At this stage, we believed that gaining more normal images was more useful than collecting reciprocal measurements of every image (that are possibly not related to the same state of tracer arrival).

Noise reduction is crucial, as the changes in the data linked to the tracer arrival are of the same order of magnitude as the data error. Here, we were able to maintain the reciprocal error distribution between -2 and $2 \%$, except for a few outliers that were removed from all data sets. The standard deviation of the reciprocal error distribution is also lower than $0.5 \%$. This is satisfactory given the higher percentage change in the data linked to the tracer arrival (a few percentage points)

\section{DEPTH OF INVESTIGATION}

The depth of investigation is defined by the depth below which the electrical structures do not depend on the surface data anymore (Oldenburg and Li, 1999). Below this depth, it is assumed that electrical structures are linked to the initial and prior or reference model used in the inversion process. Therefore, if changes in the electrical structures (e.g., forced by a salt tracer test) are located below the depth of investigation, we assume that they will not affect the surface data and that these changes cannot be retrieved in the timelapse images. Thus, we decided to filter all ERT images by selecting an appropriate cutoff value for the depth-of-investigation indicator. This way, we avoid interpreting artifacts as changes in resistivity resulting from the tracer arrival.

Several techniques exist to estimate the depth of investigation or to identify possible artifacts in the electrical structures. Among them, the resolution (e.g., Alumbaugh and Newman, 2000; Friedel, 2003; Oldenborger and Routh, 2009) or sensitivity (e.g., Nguyen et al., 2009) matrix analysis and/or the depth of investigation (DOI) index (e.g., Oldenburg and Li, 1999; Marescot et al., 2003) analysis are often used. We used the relative sensitivity matrix computed by the Res2Dinv software (Loke and Barker, 1996) because this parameter gives a direct indication of the sensitivity of measurements subject to changes in the electrical structures.

To estimate the right cutoff value for the sensitivity, we performed extra tests in the Havelange site on 22 April 2010. We used an EM39 electromagnetic induction probe (Geonics Limited) to recover information about the bulk electrical resistivity in the injection well. Because the gravel pack (radius of $62.5 \mathrm{~mm}$ ) only slightly influences apparent electrical resistivity measurements (McNeill, 1986), we assumed that the EM39 log is sufficiently representative of the bulk electrical resistivity. We took measurements every half meter, starting from the bottom of the well. Because this technique requires PVC casing, we stopped measuring once we arrived near the metal casing that supports overburden ( $5 \mathrm{~m}$ from the surface).

Preliminary tests conducted in February 2010 included an ERT profile centered on the injection-well position. These tests were designed to compare several acquisition parameters to find the best compromise between good data quality and rapid acquisition. The data acquired using the same acquisition parameters as the tracer test parameters were inverted by using the same parameters as for the tracer test experiment, and an ERT log was extracted at the well's position. We compared this ERT log with the EM39 log to find a correct cutoff value. We believe that this methodology gives a good estimate of the depth of investigation even if ERT and EM39 do not investigate the same volume of material. Often, the cutoff value is arbitrarily chosen (Oldenburg and $\mathrm{Li}$, 1999; Marescot et al., 2003), whereas here we base our choice on the comparison between two values of the resistivity obtained independently.

A strong discrepancy between the ERT and EM39 logs can be seen at a depth of $32 \mathrm{~m}$ (Figure 2, discrepancy C). At this depth, the relative sensitivity value is about 0.1 , which is our cutoff value for depth of investigation. This relative sensitivity cutoff value was applied on the time-lapse images to avoid interpreting artifacts at depth.

The depth of investigation in the central part of the images is sufficient with $30 \mathrm{~m}$ for $\mathrm{P} 1$ and $50 \mathrm{~m}$ for $\mathrm{P} 2$. Indeed, this is $10 \mathrm{~m}$ below the expected changes of electrical resistivity (near $20 \mathrm{~m}$ deep) for $\mathrm{P} 1$ and $30 \mathrm{~m}$ below for P2. The electrical resistivity images and their relative sensitivity images are presented in Figure 3 for P1 and in Figure 4 for P2.

\section{BACKGROUND-RESISTIVITY VARIATIONS AND TIME-LAPSE INVERSION}

To set a cutoff value for the percentage change in resistivity that will separate physically based anomalies due to the tracer arrival from artifacts caused by noise, two different background measurements were taken on 15 and 16 March 2010, just before the start of injection, for both profiles. These data were inverted in a time-lapse

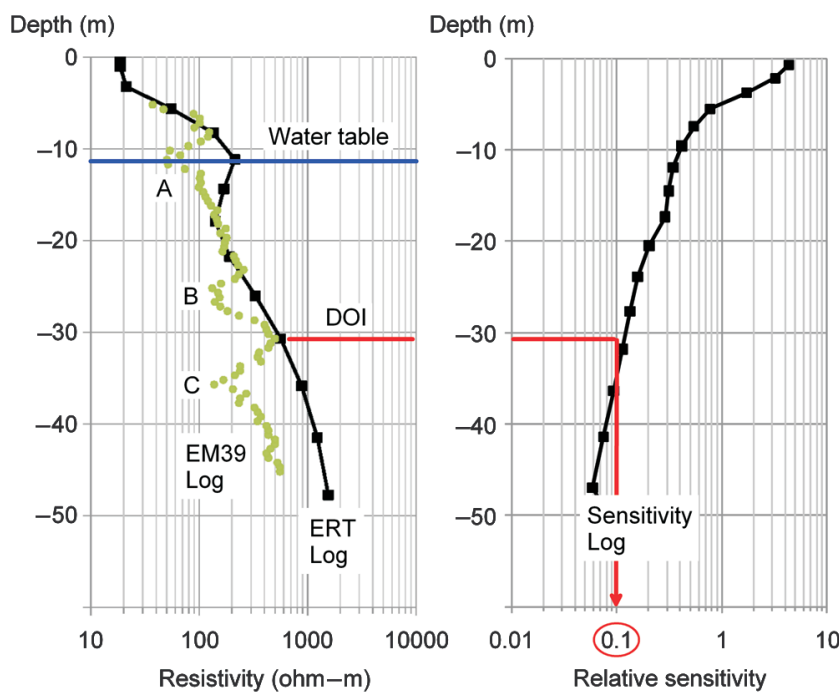

Figure 2. Resolution indicators are essential to avoid misinterpretation of the inverted electrical structures or the anomalous percentage changes in resistivity. We estimated the relative sensitivity cutoff value by comparing an EM39 log and an ERT profile centered on the injection-well position. The ERT log is extracted from the ERT image (dipole-dipole configuration, all acquisition and inversion parameters being the same as the profiles used to monitor the salt tracer propagation) and compared with the EM39 log. The first discrepancy between the ERT and EM39 logs (A) is situated near the water-table depth. The second discrepancy (B) is at a depth of $25 \mathrm{~m}$. The strongest discrepancy (C) is situated near a depth of $30 \mathrm{~m}$. Below this depth, the ERT log never corresponds with the EM39 log again, so we conclude the ERT value is erroneous. We therefore used the relative sensitivity value at $30 \mathrm{~m}$ as a cutoff value $(0.1)$ 
framework to estimate the time-lapse background-resistivity variations between two images where no changes should be observed.

The results of this time-lapse inversion are presented in Figure 5 in the form of a histogram of percentage changes in resistivity. Note that we used the following convention to calculate this percentage change

$$
\mathrm{pc}=100 \% \frac{\left(\rho_{0}-\rho_{\mathrm{T}}\right)}{\rho_{0}}
$$

The percentage change in resistivity is pc, wheras $\rho_{0}$ and $\rho_{\mathrm{T}}$ are, respectively, the electrical resistivity of the background image and the resistivity of the image at time T. Following this equation, a decrease in electrical resistivity, e.g., due to the salt tracer arrival, will result in an increase of the percentage change in resistivity.

Figure 5 shows that almost every value of percentage change in resistivity (for $\mathrm{P} 1$ and $\mathrm{P} 2$ ) is between -3 and $3 \%$. This value can be considered to be the resistivity changes due to "background" noise. Because we expected positive values for the percentage change in resistivity due to the tracer arrival, we used $3 \%$ as a cutoff value above which time-lapse variations are significant.

Figure 6 shows an example of the application of both cutoff values (sensitivity and background variations) on a time-lapse image enhancing the identification of the tracer arrival. The cutoff value linked to the relative sensitivity matrix mainly plays a role at depth, and the cutoff linked to the background variations removes some slight artifacts that cannot be interpreted because they are not significant. Note that the filter related to the background-resistivity variations has the greater contribution.
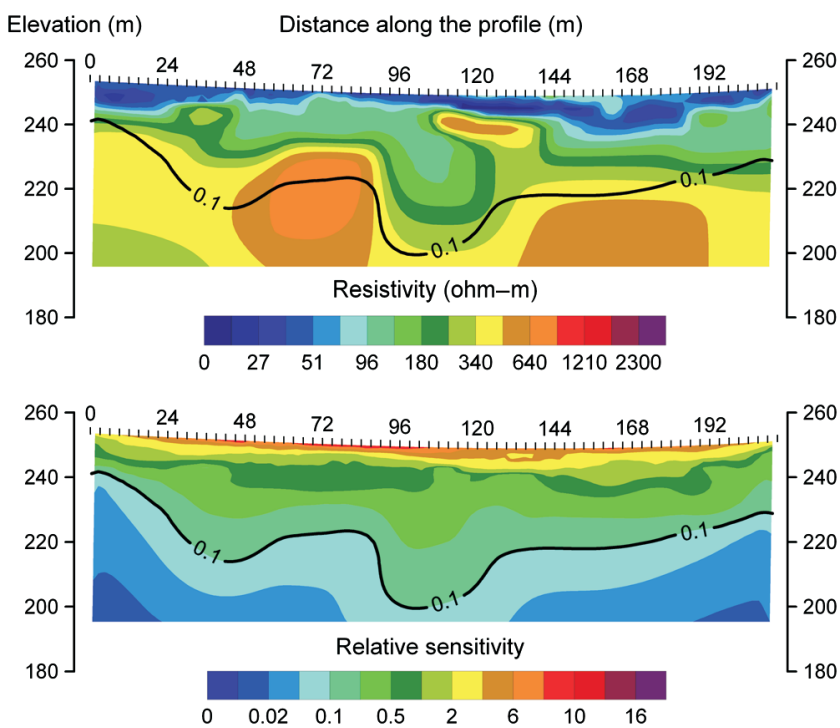

Figure 3. The electrical structures of P1 are quite conductive (less than $400 \Omega \mathrm{m}$ ), having resistivities consistent with more fractured or karstified limestones. The more conductive layer (less than $100 \Omega \mathrm{m}$ ) at the top of the inverted model has a thickness of $10 \mathrm{~m}$ and is related to overburden and weathered limestones. The water table is at an elevation of about $240 \mathrm{~m}$. The " 0.1 " relative sensitivity contour line indicates the depth of investigation (an elevation of about $220 \mathrm{~m}$ ). Below this elevation, electrical structures should be interpreted with caution because they are not strongly dependent on the measured data.
For the background images, data inversion was performed with the Res2Dinv software (Loke and Barker, 1996), using a blocky inversion also called robust or L1-norm-model constraint inversion (Loke et al., 2003). This regularization technique is particularly suited when dealing with sharp boundaries (e.g., fractured or karstified zones) because the penalty for higher resistivity gradients in the objective function is not as large as it is in the L2 norm. Table 3 summarizes these inversion parameters.

Several time-lapse inversion schemes were tested, namely strictly independent static inversion versus joint inversion using a crossmodel constraint, and these led to similar results. A detailed comparison of different time-lapse inversion techniques is out of the scope of this study. Here, we inverted the differences in the electrical resistances and we used a robust smoothness constraint on the spatial changes.

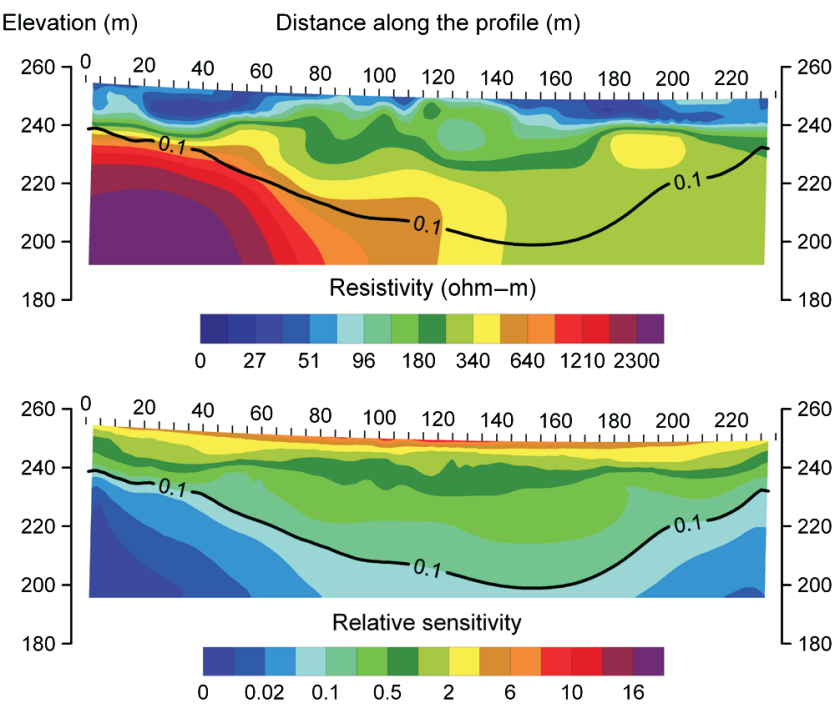

Figure 4. The electrical structures of $\mathrm{P} 2$ are similar to those of $\mathrm{P} 1$ (Figure 3).

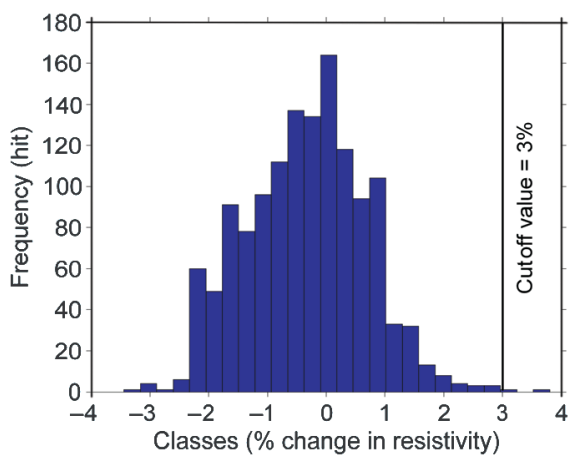

Figure 5. The estimation of the background-resistivity variation is essential to prevent the misinterpretation of time-lapse structures. We acquired two background ERT data sets for P1 and P2 and inverted them in a time-lapse framework. The background-resistivity variations are presented here in the form of a histogram $(\mathrm{P} 1+\mathrm{P} 2)$. As these random noise variations are less than $3 \%$, we took values above $3 \%$ to indicate anomalous zones (because we expect a positive anomaly from the tracer arrival, in agreement with equation 1). 
We decided to present all the results with a final root-meansquare error of $2 \%$ which is the level of noise that was estimated with the reciprocal measurements. We assumed a constant level of noise between every time-lapse sequence. Note that the percentage change in resistivity was calculated with the first background image taken 15 March 2010 as a reference (resulting images are quite identical, with the second background image as a reference).

\section{RESULTS}

The static images are shown in Figure 3 (P1) and Figure 4 (P2). Both ERT images present a shallow layer of conductive material (from 10 to some $60 \Omega \mathrm{m}$ ) with a thickness varying between 5 and $10 \mathrm{~m}$. This layer is related with overburden (mostly clay and sand) as well as the weathered part of the limestone bedrock. The water table was measured at a depth of $11.38 \mathrm{~m}$ during the days of the tracer test.

Except for this shallow conductive layer, the electrical resistivity distribution is quite homogeneous, with resistivity values from 100 to $300 \Omega \mathrm{m}$. Because the groundwater electrical resistivity is equal to $14.3 \Omega \mathrm{m}$, the electrical formation factor lies between seven and

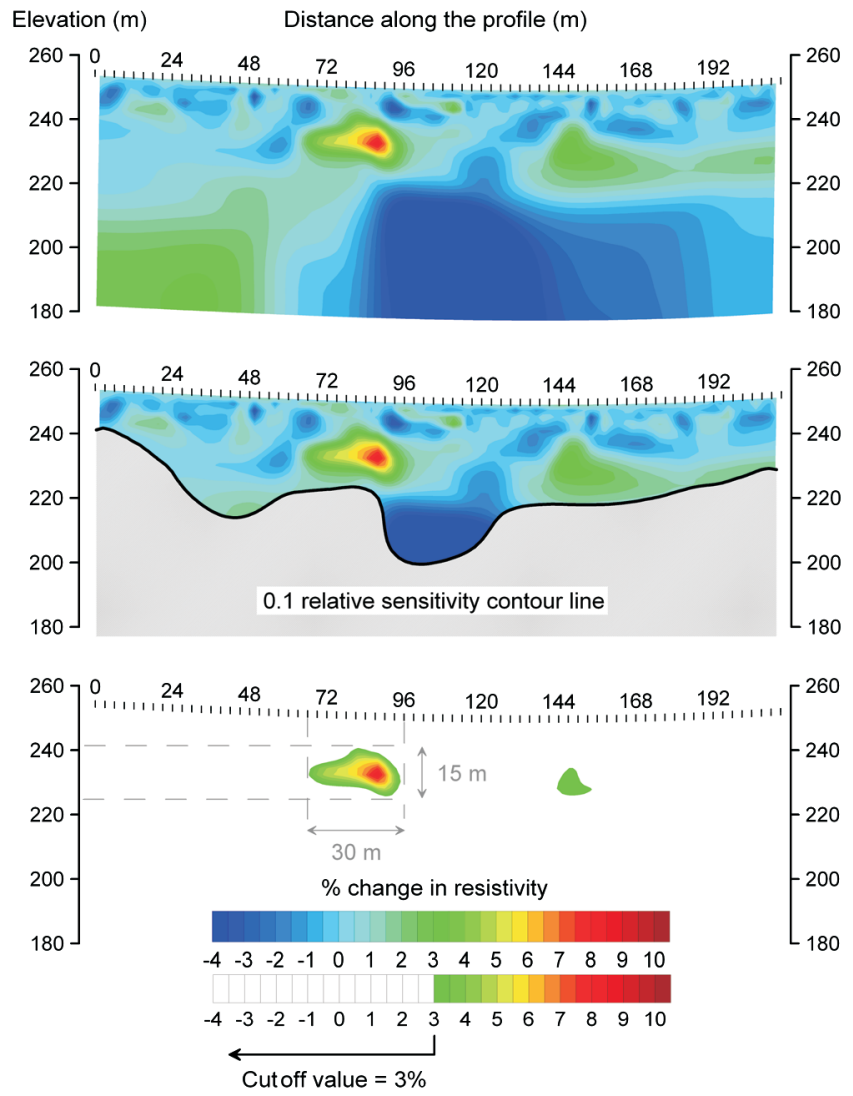

Figure 6. We applied two different filters on our time-lapse images (top panel). The first filter is linked to the depth of investigation and is useful to filter artifacts at depth (middle panel). In this case, we used a cutoff value of 0.1 for the relative sensitivity parameter. The second filter is related to the background-resistivity variations (cutoff value $=3 \%$ ) and removes artifacts due to noise (bottom panel). The remaining anomaly has a maximum value near $8 \%$ in this image (corresponding to the image $\mathrm{T} 3$ of $\mathrm{P} 1$ for the first test), which is more than the variation due to noise $(<3 \%)$.
21 and this seems to indicate mostly fractured or at least uncompacted limestones (Robert et al. 2011).

The salt tracer arrival in the first ERT profile can be observed clearly between 70 and $90 \mathrm{~m}$ and at a mean elevation of $235 \mathrm{~m}$, which is about $20 \mathrm{~m}$ below the ground surface (Figure 7 and Figure 8) for both injections. It confirms the preferential flow and solute-transport path. The shape of this arrival is compact and circular, with a width of $20 \mathrm{~m}$. The actual shape of the preferential path

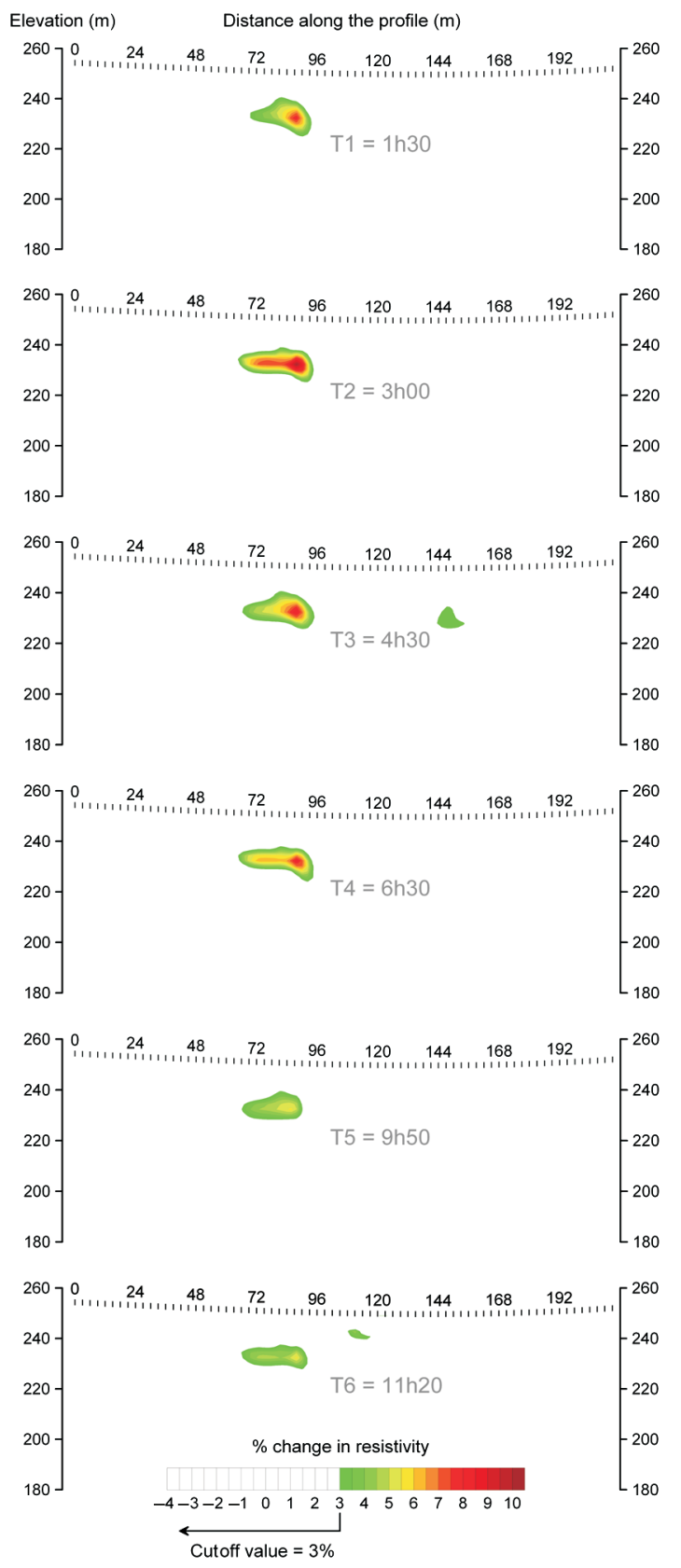

Figure 7. The first ERT profile P1 (placed $15 \mathrm{~m}$ from the injection well) presents a clear tracer arrival right after the first time-lapse image (90 minutes after the beginning of the first test: $38 \mathrm{~g} / \mathrm{L}$ ). Subsequent time-lapse images confirm that the tracer is transported through a preferential path, with the anomaly diminishing after 8 hours and 30 minutes. 
is difficult to image because of the inherent smoothing of the ERT method.

The tracer did not sink due to the density difference between the injected solution and natural groundwater because its depth in both time-lapse images is still near $20 \mathrm{~m}$ (which corresponds to the injection depth). This is an indication of a rapid horizontal groundwater flow. Moreover, the localization of the tracer arrival

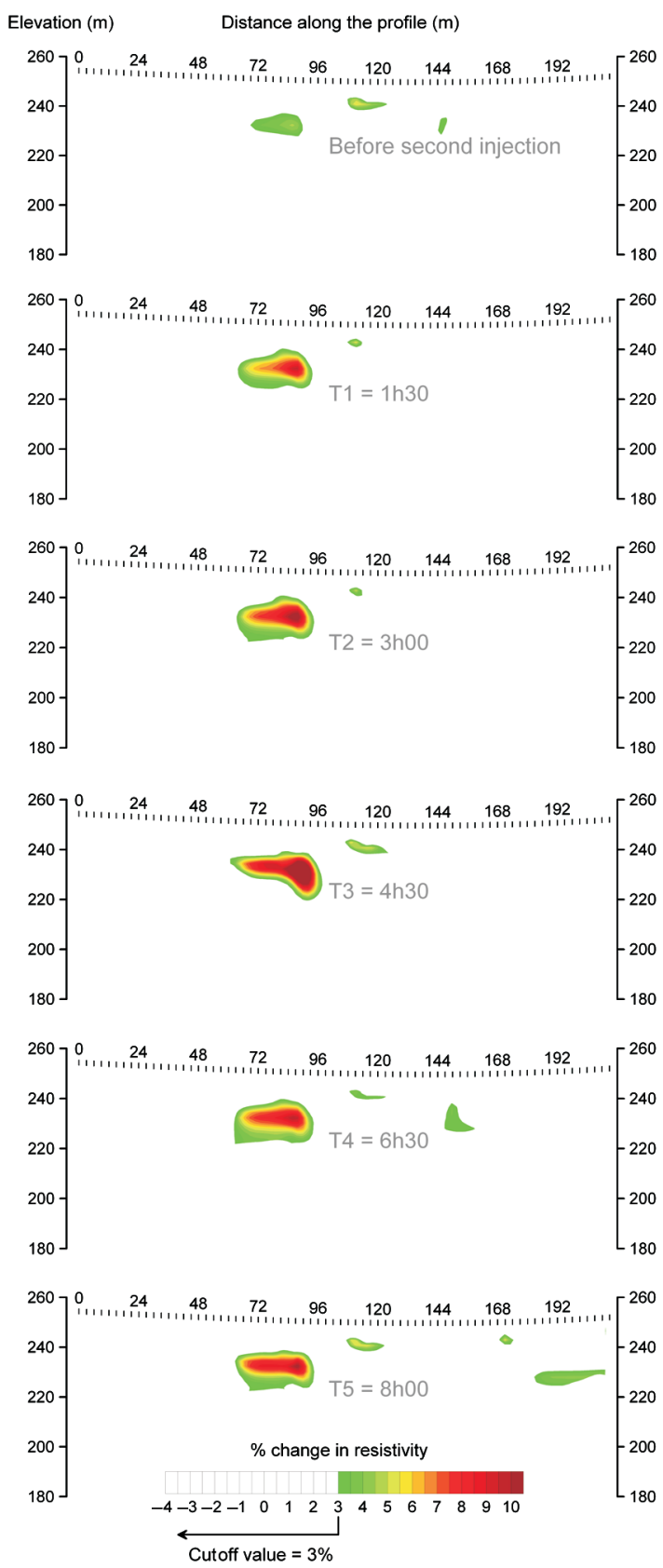

Figure 8. The first ERT profile P1 (placed $15 \mathrm{~m}$ from the injection well) presents some remaining tracer presence before the second injection. It can be seen that right after the first time-lapse image (90 minutes after the beginning of the second test: $154 \mathrm{~g} / \mathrm{L}$ ), the percentage in resistivity increases again, with the anomaly being stronger than that of the first injection.

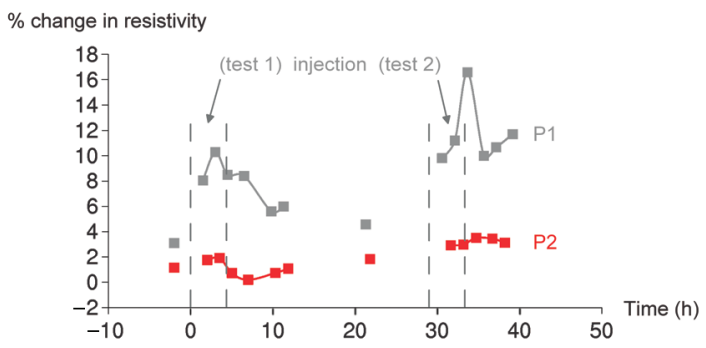

$\%$ change in resistivity

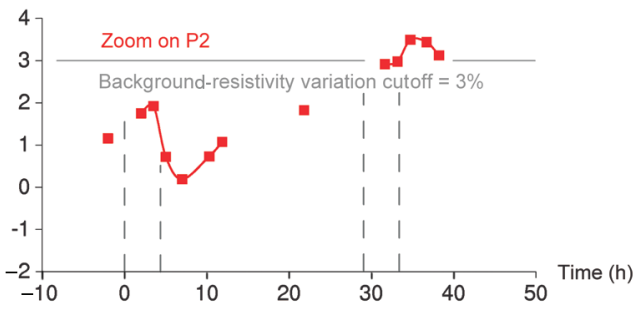

Figure 9. The high dilution effects and the high transport velocities expected in the area are confirmed with this experiment. We present here the breakthrough curves for P1 and P2 (for the cell with the maximum percentage change). The tracer transport is rapid because the first image taken after the injection already presents a clear tracer arrival (in P1). The high dilution effects can be seen in the breakthrough curve corresponding to $\mathrm{P} 2$ (which was placed $30 \mathrm{~m}$ away from the injection well). Only the second part related to the second test $(154 \mathrm{~g} / \mathrm{L})$ is physically interpretable. The first part of the breakthrough curve remains below the background-resistivity-variations cutoff $(3 \%)$ and cannot be interpreted as the tracer arrival.

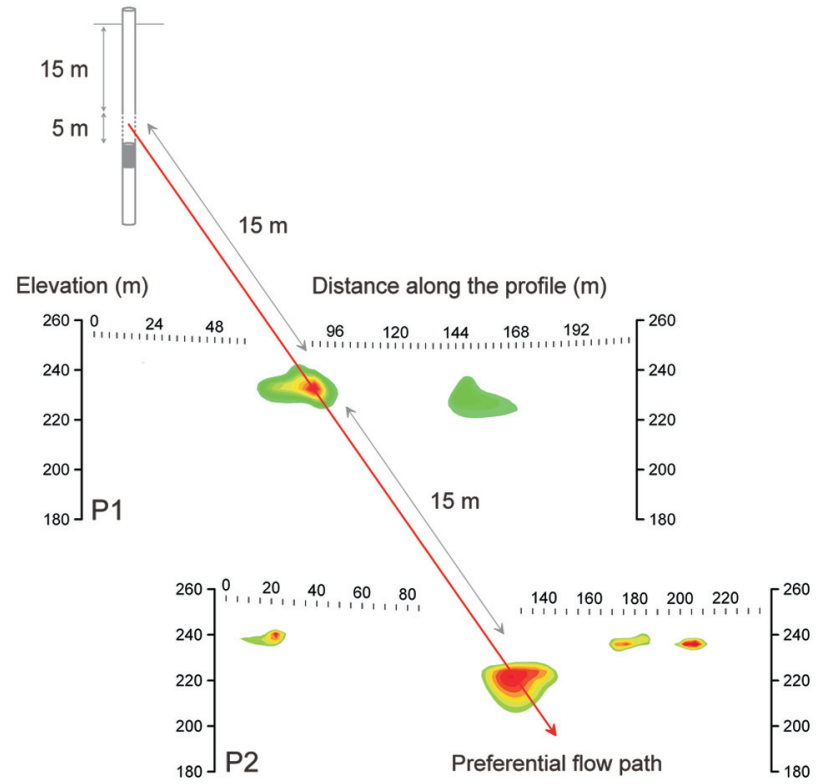

Figure 10. By continuously injecting a salt tracer into a known fractured zone, we were able to image its propagation through a preferential path with ERT images. We counterbalanced the high dilution effects with the injection of higher salt concentration $(154 \mathrm{~g} / \mathrm{L}$ in the second test). We also accounted for the high transport velocities by injecting the tracer continuously during 4 hours. This experiment was a success and proves that the methodology we describe is practical in complexly fractured aquifers and at a higher scale. 
Table 4. A better temporal resolution could have been obtained with others ERT acquisition parameters. With the last acquisition procedure of this table (the more rapid), we could almost quadruple the temporal resolution for P1 (almost four profiles instead of one every $90 \mathrm{~min}$ ). With the same procedure, the temporal resolution for P2 would have been doubled. Note that the Rs check option allows the measurement and storage of the contact resistances and $T_{\text {on }}$ is the transmitter-current-injection time window.

\begin{tabular}{|c|c|c|c|c|c|}
\hline ERT profile & Data points/Injection pairs & $\begin{array}{c}\mathrm{T}_{\text {on }}=1 \mathrm{~s} \\
\text { 3-6 stacks Rs check }\end{array}$ & $\begin{array}{l}\mathrm{T}_{\text {on }}=1 \mathrm{~s} \\
3-6 \text { stacks }\end{array}$ & $\begin{array}{l}\mathrm{T}_{\text {on }}=1 \mathrm{~s} \\
2-3 \text { stacks }\end{array}$ & $\begin{array}{l}\mathrm{T}_{\mathrm{on}}=0.5 \mathrm{~s} \\
2-3 \text { stacks }\end{array}$ \\
\hline P1 (72 electrodes) & $1225 / 434$ & $55 \min$ & $43 \min$ & $36 \min$ & $24 \min$ \\
\hline P2 (48 electrodes) & $629 / 198$ & $26 \min$ & $20 \min$ & $18 \min$ & $12 \min$ \\
\hline
\end{tabular}

is not far from the estimated local direction of flow $\left(\mathrm{N} 5^{\circ} \mathrm{E}\right.$ to $\mathrm{N} 10^{\circ} \mathrm{E}$, and not $\mathrm{N} 15^{\circ} \mathrm{E}$ as previously estimated).

A change of about $8 \%$ in terms of resistivity at T1, 1.5 hours after the start of the first injection, indicates the first observation of the tracer (Figure 7). The percentage change in resistivity then increases without any change in the shape of the anomaly for time T2 (3 hours, $\sim 10 \%)$, where it reaches a plateau until time T4 (6.5 hours, $\sim 8 \%)$ before decreasing at times T5 $(\sim 10$ hours, $\sim 6 \%)$ and T6 ( $\sim 11.5$ hours, $\sim 6 \%$ ) and almost totally fading (a day after stopping the injection). Remains of the tracer $(\sim 4 \%)$ are nonetheless still observed before the start of injection of the second tracer solution $(154 \mathrm{~g} / \mathrm{L})$. Results for the second injection are similar except that the percentage change in resistivity is almost doubled (Figure 8). Moreover, the overall shape of the anomaly stays constant for both injection experiments. This is another indication that the tracer is transported through a preferential path.

Results can be visualized by drawing breakthrough curves (percentage change in resistivity over time) for selected cells of the electrical resistivity model (e.g., Vanderborght et al., 2005). An example for the cell that presented the maximum percentage change in resistivity is presented for both profiles (P1 and P2) in Figure 9.

The breakthrough curves for both ERT profiles clearly show that the values of percentage change in resistivity are doubled between the two tests. However, the concentration of salt in the first injection $(38 \mathrm{~g} / \mathrm{L})$ was not enough to obtain a clear arrival in the second ERT profile (placed at $30 \mathrm{~m}$ from the injection well). The values are below the time-lapse background-resistivity variation (about 3\%) and cannot be interpreted significantly as a tracer arrival (Figure 9). The second injection at $154 \mathrm{~g} / \mathrm{L}$ shows an arrival (around 3.5\%) of the tracer. The behavior is similar to the one for P1. Figure 10 shows the results of one time $T$ for both ERT profiles and proves the continuity in shape and position of the preferential flow path identified here.

These breakthrough curves are also helpful to pick a first-arrival time and to calculate its corresponding velocity. It is however difficult to pick a first-arrival time here because the tracer had already passed during the first image captured 90 minutes after the start of the injection. This means that the first tracer arrival time is clearly below 90 minutes. Therefore, the first-arrival velocity has a minimum value of $10 \mathrm{~m} /$ hour and could be faster if the tracer arrived sooner. Such transport-velocity values clearly confirm the expected preferential flow and solute-transport path.

\section{CONCLUSIONS AND RECOMMENDATIONS}

ERT monitoring of salt tracer tests can be useful in estimating new well positions, sampling rate, and tracer concentration. We successfully highlighted a preferential flow and solute-transport path in a very heterogeneous aquifer (a carboniferous fractured limestone aquifer in southern Belgium). To our knowledge, working at this small-basin scale is quite rare although very important because hydrogeologists can directly use the information obtained in groundwater flow and solute transport modeling.

Over a period of 4 hours, we continuously injected a salt tracer in a previously identified fracture zone, and we monitored its propagation with two transverse ERT profiles. Two different salt solutions (38 and $154 \mathrm{~g} / \mathrm{L}$ ) were injected and this allowed us to image the tracer arrival despite the strong dilution effects and the inherent smoothing of ERT.

In terms of geophysical imaging, we tested different electrode spacing ( $3 \mathrm{~m}$ on the profile closest to the injection well and $5 \mathrm{~m}$ on the more distant profile) to deal with the resolution and the depth of investigation of our resulting images. The analysis of the relative sensitivity matrix associated with an EM39 log helped us to estimate the depth of investigation of both profiles $(30$ and $50 \mathrm{~m}$ for the proximal and distal profiles, respectively). Two background profiles were taken to estimate the resistivity variations due to background noise, which helped us to discriminate real tracer arrival from noise artifacts.

ERT images allowed us to characterize the tracer arrival in terms of width, depth and concentration by monitoring the percentage change in resistivity for both profiles. Some resistivity breakthrough curves were also drawn to estimate the first-arrival time and the corresponding velocity. This allowed us to confirm the expected high transport velocities and the strong dilution effects but also to obtain some information that could be crucial to set up a classic tracer test.

This study proved that ERT can be used to qualitatively monitor very rapid solute transport ( $>10 \mathrm{~m} /$ hour) when the data acquisition procedure is well defined. Given the results of our study, some points could be improved in future work. First, the longitudinal profile did not give results. Therefore, we believe that gaining more time-lapse images for the transverse profiles would have been more instructive and less risky. This way, we could have had a better estimate of the first-arrival time.

We used a transmitter-current-injection time window of 1 second to obtain a good data quality. A refined breakthrough curve could be obtained by using half a second for this time window without adding too much noise in the data. Decreasing the number of stacks from 3-6 to 2-3 will also allow more frequent sampling of the ERT image and hence a better temporal resolution of the tracer recovery.

Finally, we injected the salt tracer solution at the top of the well. As a consequence, the tracer was already (strongly) diluted before flowing through the fractured zone. We therefore recommend 
injecting the tracer at the depth of interest (in our case, the fractured zone).

With all these changes in the acquisition procedure, we could have obtained higher resistivity changes and almost have quadrupled the temporal resolution for P1. Table 4 presents the acquisition time of both ERT profiles with regard to different parameters sets.

Further developments of this work will be to model groundwater flow and solute transport in the calcareous syncline structure. To do so, further geophysical and hydrogeological investigations as well as new boreholes are necessary to fully conceptualize this aquifer. For this reason, self-potential and ERT profiles are currently being conducted along with hydrogeological investigations to acquire information for the groundwater flow model conceptualization.

\section{REFERENCES}

al Hagrey, S. A., and J. Michaelsen, 1999, Resistivity and percolation study of preferential flow in vadose zone at Bokhorst, Germany: Geophysics, 64, 746-753, doi: 10.1190/1.1444584.

Al-Saigh, N. H., Z. S. Mohammed, and M. S. Dahham, 1994, Detection of water leakage from dams by self-potential method: Engineering Geology, 37, 115-121.

Alumbaugh, D. L., and G. A. Newman, 2000, Image appraisal for 2-D and 3-D electromagnetic inversion: Geophysics, 65, 1455-1467.

Aubert, M., and Q. Y. Atangana, 1996, Self-potential method in hydrogeological exploration of volcanic areas: Ground Water, 34, 1010-1016.

Barker, R., and J. Moore, 1998, The application of time-lapse electrical tomography in groundwater studies: The Leading Edge, 17, 1454-1458.

Berkowitz, B., 2002, Characterizing flow and transport in fractured geological media: A review: Advances in Water Resources, 25, 861-884.

Bevc, D., and H. F. Morrison, 1991, Borehole-to-surface electrical resistivity monitoring of a salt water injection experiment: Geophysics, 56, 769-777.

Binley, A., G. Cassiani, R. Middleton, and P. Winship, 2002a, Vadose zone flow model parameterisation using cross-borehole radar and resistivity imaging: Journal of Hydrology, 267, 147-159.

Binley, A., S. Henry-Poulter, and B. Shaw, 1996a, Examination of solute transport in an undisturbed soil column using electrical resistance tomography: Water Resources Research, 32, 763-769.

Binley, A., B. Shaw, and S. Henry-Poulter, 1996b, Flow pathways in porous media: Electrical resistance tomography and dye staining image verification: Measurement Science and Technology, 7, 384-390.

Binley, A., P. Winship, L. J. West, M. Pokar, and R. Middleton, 2002b, Seasonal variation of moisture content in unsaturated sandstone inferred from borehole radar and resistivity profiles: Journal of Hydrology, 267, $160-172$.

Boadu, F. K., J. Gyamfi, and E. Owusu, 2005, Determining subsurface fracture characteristics from azimuthal resistivity surveys: A case study at Nsawam, Ghana: Geophysics, 70, no. 5, B35-B42.

Bolève, A., A. Revil, F. Janod, J. L. Mattiuzzo, and J. J. Fry, 2009, Preferential fluid flow pathways in embankment dams imaged by self-potential tomography: Near Surface Geophysics, 7, 447-462.

Brouyère, S., J. Gesels, P. Goderniaux, P. Jamin, T. Robert, L. Thomas, A. Dassargues, J. Bastien, F. Vanwittenberge, A. Rorive, F. Dossin, J.-L. Lacour, D. Le Madec, P. Nogarède, and V. Hallet, 2009, Caractérisation hydrogéologique et support à la mise en œuvre de la Directive Européenne 2000/60 sur les masses d'eau souterraine en Région Wallonne (Projet Synclin'EAU): Délivrable - D.3.12 - Rapport sur la caracterisation hydraulique des aquifères et l'estimation des ressources en eaux souterraines - Partie RWM021: Convention RW et SPGEAquapole.

Cassiani, G., V. Bruno, A. Villa, N. Fusi, and A. M. Binley, 2006, A saline tracer test monitored via time-lapse surface electrical resistivity tomography: Journal of Applied Geophysics, 59, 244-259.

Corwin, R. F., and D. B. Hoover, 1979, The self-potential method in geothermal exploration: Geophysics, 44, 226-245.

Daily, W., and A. Ramirez, 1995, Electrical resistance tomography during in-situ trichloroethylene remediation at the Savannah River site: Journal of Applied Geophysics, 33, 239-249.

Daily, W., A. Ramirez, D. LaBrecque, and W. Barber, 1995, Electrical resistance tomography experiments at the Oregon Graduate Institute: Journal of Applied Geophysics, 33, 227-237.

Daily, W., A. Ramirez, D. LaBrecque, and J. Nitao, 1992, Electrical resistivity tomography of vadose water movement: Water Resources Research, 28, 1429-1442.
Day-Lewis, F., J. Lane, and S. Gorelick, 2006, Combined interpretation of radar, hydraulic, and tracer data from a fractured-rock aquifer near Mirror Lake, New Hampshire, USA: Hydrogeology Journal, 14, $1-14$.

Day-Lewis, F. D., J. M. Harris, and S. M. Gorelick, 2002, Time-lapse inversion of crosswell radar data: Geophysics, 67, 1740-1752.

Day-Lewis, F. D., J. W. Lane, J. M. Harris, and S. M. Gorelick, 2003, Timelapse imaging of saline-tracer transport in fractured rock using differenceattenuation radar tomography: Water Resources Research, 39, 1290, doi: 10.1029/2002WR001722.

Fagerlund, F., and G. Heinson, 2003, Detecting subsurface groundwater flow in fractured rock using self-potential (SP) methods: Environmental Geology, 43, 782-794.

Fetter, C. W., 2001, Applied hydrogeology (4th ed.): Prentice-Hall.

Fournier, C., 1989, Spontaneous potentials and resistivity surveys applied to hydrogeology in a volcanic area: Case history of the Chaîne des Puys (Puy-de-Dôme, France): Geophysical Prospecting, 37, 647-668.

Friedel, S., 2003, Resolution, stability and efficiency of resistivity tomography estimated from a generalized inverse approach: Geophysical Journal International, 153, 305-316.

Hao, Y., T.-C. J. Yeh, J. Xiang, W. A. Illman, K. Ando, K.-C. Hsu, and C.-H. Lee, 2008, Hydraulic tomography for detecting fracture zone connectivity: Ground Water, 46, 183-192.

Hayley, K., L. R. Bentley, and M. Gharibi, 2009, Time-lapse electrical resistivity monitoring of salt-affected soil and groundwater: Water Resources Research, 45, w07425, doi: 10.1029/2008wr007616.

Illman, W. A., A. J. Craig, and X. Liu, 2008, Practical issues in imaging hydraulic conductivity through hydraulic tomography: Ground Water, 46, 120-132.

Illman, W. A., and D. M. Tartakovsky, 2006, Asymptotic analysis of cross-hole hydraulic tests in fractured granite: Ground Water, 44, $555-563$.

Jardani, A., J.-P. Dupont, and A. Revil, 2006, Self-potential signals associated with preferential groundwater flow pathways in sinkholes: Journal of Geophysical Research, 111, B09204, doi: 10.1029/ 2005JB004231.

Jardani, A., A. Revil, A. Bolève, A. Crespy, J.-P. Dupont, W. Barrash, and B. Malama, 2007, Tomography of the Darcy velocity from self-potential measurements: Geophysical Research Letters, 34, L24403, doi: 10 1029/2007GL031907.

Kemna, A., J. Vanderborght, B. Kulessa, and H. Vereecken, 2002, Imaging and characterisation of subsurface solute transport using electrical resistivity tomography (ERT) and equivalent transport models: Journal of Hydrology, 267, 125-146.

Koestel, J., A. Kemna, M. Javaux, A. Binley, and H. Vereecken, 2008, Quantitative imaging of solute transport in an unsaturated and undisturbed soil monolith with 3D ERT and TDR: Water Resources Research, 44, W12411, doi: 10.1029/2007WR006755

LaBrecque, D. J., M. Miletto, W. Daily, A. Ramirez, and E. Owen, 1996, The effects of noise on Occam's inversion of resistivity tomography data: Geophysics, 61, 538-548.

Liu, S., T.-C. J. Yeh, and R. Gardiner, 2002, Effectiveness of hydraulic tomography: Sandbox experiments: Water Resources Research, 38, 1034, doi: $10.1029 / 2001 \mathrm{WR} 000338$.

Loke, M. H., I. Acworth, and T. Dahlin, 2003, A comparison of smooth and blocky inversion methods in 2D electrical imaging surveys: Exploration Geophysics, 34, 182-187.

Loke, M. H., and R. D. Barker, 1996, Rapid least-squares inversion of apparent resistivity pseudosections by a quasi-Newton method: Geophysical Prospecting, 44, 131-152.

Marescot, L., M. H. Loke, D. Chapellier, R. Delaloye, C. Lambiel, and E. Reynard, 2003, Assessing reliability of 2D resistivity imaging in mountain permafrost studies using the depth of investigation index method: Near Surface Geophysics, 1, 57-67.

McNeill, J. D., 1986, Geonics EM39 borehole conductivity meter - Theory of operation: Geonics Limited technical note TN-20.

Miller, C. R., P. S. Routh, T. R. Brosten, and J. P. McNamara, 2008 , Application of time-lapse ERT imaging to watershed characterization: Geophysics, 73, no. 3, G7-G17.

Müller, K., J. Vanderborght, A. Englert, A. Kemna, J. A. Huisman, J. Rings, and $\mathrm{H}$. Vereecken, 2010, Imaging and characterization of solute transport during two tracer tests in a shallow aquifer using electrical resistivity tomography and multilevel groundwater samplers: Water Resources Research, 46, W03502, doi: 10.1029/2008WR007595.

Nguyen, F., A. Kemna, A. Antonsson, P. Engesgaard, O. Kuras, R. Ogilvy, J. Gisbert, S. Jorreto, and A. Pulido-Bosch, 2009, Characterization of seawater intrusion using 2D electrical imaging: Near Surface Geophysics, 7 , 377-390.

Nimmer, R. E., and J. L. Osiensky, 2002a, Using mise-a-la-masse to delineate the migration of a conductive tracer in partially saturated basalt: Environmental Geosciences, 9, 81-87, doi: 10.1046/j.1526-0984.2002 $.92005 . x$. 
Nimmer, R. E., and J. L. Osiensky, 2002b, Direct current and self-potential monitoring of an evolving plume in partially saturated fractured rock: Journal of Hydrology, 267, 258-272.

Nimmer, R. E., J. L. Osiensky, A. M. Binley, K. F. Sprenke, and B. C. Williams, 2007, Electrical resistivity imaging of conductive plume dilution in fractured rock: Hydrogeology Journal, 15, 877-890.

Oldenborger, G. A., M. D. Knoll, P. S. Routh, and D. J. LaBrecque, 2007, Time-lapse ERT monitoring of an injection/withdrawal experiment in a shallow unconfined aquifer: Geophysics, 72, F177-F187.

Oldenborger, G. A., and P. S. Routh, 2009, The point-spread function measure of resolution for the 3-D electrical resistivity experiment: Geophysical Journal International, 176, 405-414.

Oldenburg, D. W., and Y. Li, 1999, Estimating depth of investigation in DC resistivity and IP surveys: Geophysics, 64, 403-416.

Osiensky, J. L., and P. R. Donaldson, 1995, Electrical flow through an aquifer for contaminant source leak detection and delineation of plume evolution: Journal of Hydrology, 169, 243-263.

Park, S., 1998, Fluid migration in the vadose zone from 3-D inversion of resistivity monitoring data: Geophysics, $\mathbf{6 3}, 41-51$.

Porsani, J. L., V. R. Elis, and F. Y. Hiodo, 2005, Geophysical investigations for the characterization of fractured rock aquifers in Itu, SE Brazil: Journal of Applied Geophysics, 57, 119-128.

Post, V. E. A., 2005, Fresh and saline groundwater interaction in coastal aquifers: Is our technology ready for the problems ahead?: Hydrogeology Journal, 13, 120-123.

Ptak, T., M. Piepenbrink, and E. Martac, 2004, Tracer tests for the investigation of heterogeneous porous media and stochastic modelling of flow and transport - A review of some recent developments: Journal of Hydrology, 294, 122-163.

Ramirez, A., W. Daily, A. Binley, D. J. LaBrecque, and D. Roelant, 1996, Detection of leaks in underground storage tanks using electrical resistance tomography methods: Journal of Environmental and Engineering Geophysics, 1, 189-203.

Revil, A., L. Cary, Q. Fan, A. Finizola, and F. Trolard, 2005, Self-potential signals associated with preferential ground water flow pathways in a buried paleo-channel: Geophysical Research Letters, 32, L07401, doi: 10 1029/2004GL022124.

Revil, A., P. A. Pezard, and P. W. J. Glover, 1999, Streaming potential in porous media 1. Theory of the zeta potential: Journal of Geophysical Research, 104, B9, doi: 10.1029/1999JB900089.

Robert, T., A. Dassargues, S. Brouyère, O. Kaufmann, V. Hallet, and F Nguyen, 2011, Assessing the contribution of electrical resistivity tomography (ERT) and self-potential (SP) methods for a water well drilling program in fractured/karstified limestones: Journal of Applied Geophysics, 75, 42-53.

Sharma, S. P., and V. C. Baranwal, 2005, Delineation of groundwaterbearing fracture zones in a hard rock area integrating very low frequency electromagnetic and resistivity data: Journal of Applied Geophysics, 57, 155-166.

Sill, W. R., 1983, Self-potential modeling from primary flows: Geophysics, 48, 76-86.

Singha, K., and S. M. Gorelick, 2005, Saline tracer visualized with threedimensional electrical resistivity tomography: Field-scale spatial moment analysis: Water Resources Research, 41, W05023, doi: 10.1029/ 2004WR003460

Slater, L., A. Binley, R. Versteeg, G. Cassiani, R. Birken, and S. Sandberg, 2002, A 3D ERT study of solute transport in a large experimental tank: Journal of Applied Geophysics, 49, 211-229.

Slater, L., A. M. Binley, W. Daily, and R. Johnson, 2000, Cross-hole electrical imaging of a controlled saline tracer injection: Journal of Applied Geophysics, 44, 85-102.

Slater, L., M. D. Zaidman, A. M. Binley, and L. J. West, 1997b, Electrica imaging of saline tracer migration for the investigation of unsaturated zone transport processes: Hydrology and Earth System Sciences, 1, 291-302.

Slater, L. D., A. Binley, and D. Brown, 1997a, Electrical imaging of fractures using ground-water salinity change: Ground Water, 35, 436-442.

Slater, L. D., and S. K. Sandberg, 2000, Resistivity and induced polarization monitoring of salt transport under natural hydraulic gradients: Geophysics, 65, 408-420.

Suski, B., F. Ladner, L. Baron, F. D. Vuataz, F. Philippossian, and K. Holliger, 2008, Detection and characterization of hydraulically active fractures in a carbonate aquifer: Results from self-potential, temperature and fluid electrical conductivity logging in the Combioula hydrothermal system in the southwestern Swiss Alps: Hydrogeology Journal, 16, 1319-1328.

Vanderborght, J., A. Kemna, H. Hardelauf, and H. Vereecken, 2005, Potential of electrical resistivity tomography to infer aquifer transport characteristics from tracer studies: A synthetic case study: Water Resources Research, 41, W06013, doi: 10.1029/2004WR003774.

White, P. A., 1988, Measurement of ground-water parameters using saltwater injection and surface resistivity: Ground Water, 26, 179-186.

White, P. A., 1994, Electrode arrays for measuring groundwater flow direction and velocity: Geophysics, 59, 192-201.

Wilkinson, P. B., P. I. Meldrum, O. Kuras, J. E. Chambers, S. J. Holyoake, and R. D. Ogilvy, 2010, High-resolution electrical resistivity tomography monitoring of a tracer test in a confined aquifer: Journal of Applied Geophysics, 70, 268-276.

Wu, C.-M., T.-C. J. Yeh, J. Zhu, T. H. Lee, N.-S. Hsu, C.-H. Chen, and A. F. Sancho, 2005, Traditional analysis of aquifer tests: Comparing apples to oranges?: Water Resources Research, 41, W09402, doi: 10.1029/ 2004WR003717.

Yadav, G. S., and S. K. Singh, 2007, Integrated resistivity surveys for delineation of fractures for ground water exploration in hard rock areas: Journal of Applied Geophysics, 62, 301-312.

Yeh, T.-C. J., and S. Liu, 2000, Hydraulic tomography: Development of a new aquifer test method: Water Resources Research, 36, 2095-2105, doi: 10.1029/2000WR900114.

Yin, D., and W. A. Illman, 2009, Hydraulic tomography using temporal moments of drawdown recovery data: A laboratory sandbox study: Water Resources Research, 45, W01502, doi: 10.1029/2007WR006623.

Zhu, J., and T.-C. J. Yeh, 2005, Characterization of aquifer heterogeneity using transient hydraulic tomography: Water Resources Research, 41 W07028, doi: 10.1029/2004WR003790.

Zhu, J., and T.-C. J. Yeh, 2006, Analysis of hydraulic tomography using temporal moments of drawdown recovery data: Water Resources Research, 42, W02403, doi: 10.1029/2005WR004309. 